\title{
Research on Influence of Endowment Insurance on "Knowledge-based" Labor Employment
}

\author{
Xiaohui Long \\ Hunan International Business Vocational College, Changsha, 421000, China
}

Keywords: Endowment insurance; Knowledge-based; Employment; influence

\begin{abstract}
With continuous increase of graduates years by year in China, the "knowledge-based" labor force continuously accumulates, but the employment chances don't increase accordingly, thus the problem of graduates' difficult employment becomes more and more serious, and the phenomenon that the supply has exceeded the demand in the talent market has become a commonly concerned focus in the society. Besides, the aging of population also becomes another social hot focus, and the imperfect endowment insurance system causes unoptimistic endowment condition. These two focuses are problems that China shall urgently solve, and there is close relationship between them, and the endowment insurance causes certain influence on employment. This paper mainly discusses the influence of endowment insurance on "knowledge-based" employment for the purpose of providing some reference for these two hot problems.
\end{abstract}

\section{Introduction}

China formulates endowment insurance system according to corresponding laws and regulations; as for the labor force whose labor obligation has been terminated due to the fact that their age is up to legal age, or the labor force who has to exit from labor post due to old age and loss of labor force, China guarantees their basic life through establishing the endowment insurance system. The endowment insurance belongs to one kind of social insurance, and it plays an important role in social insurance. However, the endowment insurance influences labor employment, especially the "knowledge-based" labor, and it mainly causes direct influence on employment pressure, job-hunting intention, job-hunting initiative, job satisfaction, and career. Therefore, it is very necessary to research the influence of endowment insurance on "knowledge-based" labor employment.

\section{Analysis on connotation of relevant concept}

\section{Connotation of "knowledge-based" labor}

There is a certain definition on "knowledge-based" labor, and we mainly carry out a brief analysis from perspective of broad sense and narrow sense. In terms of broad sense, the "knowledge-based" labor refers to the labor force who have certain theoretical foundation, and regard such theoretical foundation as basis of job and finally obtain excellence. In terms of narrow sense, the "knowledge-based" labor refers to graduates or in-service personnel who have accepted higher education and professional education, and the main research objective is employment behavior and concept. In order to research the influence of endowment insurance on "knowledge- based" labor employment, we shall firstly be clear about the connotation of "knowledge-based" labor, that is, labor personnel who have certain knowledge level and can make full use of knowledge in the work, and such kind of labor mainly includes graduates and personnel with work experience.

\section{Connotation of endowment insurance}

In order to clearly know the true connotation of endowment insurance, we shall carry out an analysis on relevant concept of endowment insurance. Firstly, we shall distinguish endowment insurance from old-age security. The old-age security is subordinate to social security, and this concept has no accurate definition; according to superficial meaning, the old-age security just refers to providing certain guarantee for the life of labor force after retire, and its way of representation is pension. However, the concept of endowment insurance is clear. Currently, there are mainly two 
kinds of endowment insurance in China: one is commercial endowment insurance and the other is social endowment insurance. The social endowment insurance is a kind of insurance system which is formulated by the state and society under the guidance of relevant regulations and laws, and takes personnel at national legal age and old workers whose labor capacity has lost as objects to meet their basic life demand.

\section{Connotation of pension}

Another concept related to endowment insurance is pension. China implements the pension double-track system; this system has specificity and certain time background, and it is produced in the process that the market economy replaces planned economy, that is to say, different pension for different post. For example, as for employees of public institutions, their pension is directly issued by national finance; however, the employees of individual operation enterprises can obtain the pension on the basis of paying some expense; in other words, there will be different way of pension issuing for different occupation.

\section{Connotation of employment-related concepts}

In order to research the influence of endowment insurance on "knowledge-based" labor employment, except for knowing above concepts, we shall also get a deep knowledge of employment. The employment refers to the labor activity that the labor force have been up to legal age, have corresponding labor ability, and they are willing to participate in labor and can obtain certain remuneration, and it includes employment awareness and employment behavior. The employment awareness refers to the post people want to select, and the employment behavior is the activity which directly reflects employment awareness; in other words, they are the relationship of awareness and practice.

\section{Influence of endowment insurance on "knowledge-based” labor employment}

Because the "knowledge-based" labor force refers to graduates who have graduated from professional education or higher education institutions, and also refers to in-service personnel with work experience, the following research on the influence of endowment insurance on "knowledge-based" labor employment is divided into two parts to carry out respective discussion on those two kinds of personnel.

Influence of endowment insurance on "knowledge-based” graduates' employment

As the most important part of "knowledge-based" labor force, it means that the graduates will step into work post and directly face the employment while they step into the society from campus. The graduates stand for the personnel under first employment. Then, what are the influences of endowment insurance on graduates' employment?

Influence of endowment insurance on graduates' employment preparation

(1) The endowment insurance intangibly increases graduates' employment pressure.

As the number of college graduates breaks a new peak year by year in China, the competition in talent market becomes more and more fierce; in particular, there is higher and higher requirement for talents at present, and the requirement of work experience brings great pressure to graduates, and it is also common that many posts shut the door upon graduates' face due to no experience. Meanwhile, the employment pressure is greatly related with endowment insurance. The employment pressure changes with change of awareness of endowment insurance; the stronger the awareness of endowment insurance is, the larger the employment pressure will be. This research has carried out an investigation on endowment insurance and employment pressure. According to the investigation, it can be known that the pressure for graduates with weak awareness of endowment insurance mainly comes from friends and relatives' degree of expectation, as well as economic burden of their families; as for graduates with certain awareness of endowment insurance, there is higher friends and relatives' degree of expectation, and also higher economic burden of families, thus it can be deduced that the friends and relatives' degree of expectation, economic burden of families, and external factors cause larger influence on graduates with strong awareness of endowment insurance compared to graduates with weak awareness of endowment insurance. Therefore, it is obvious that the endowment insurance 
causes great influence on graduates' employment pressure; in a word, the stronger the awareness of endowment insurance is, the larger the employment pressure will be.

(2) The endowment insurance directly influences graduates' employment initiative.

Through relevant investigation, we have carried out research on awareness of endowment insurance from weak to strong, and then it can be known that the graduates have stronger employment initiative as their awareness of endowment insurance is continuously enhanced, that is to say, they want to actively find a job to lay a firm foundation for their life of old age.

(3) The endowment insurance causes influence on graduates' employment intention.

As is known to us, while the graduates graduate, they have an employment intention upon facing tremendous future development directions, and there are mainly several kinds of factors influencing employment intention, that is, material condition, environment, region, and development potential, etc. However, the employment intention is directly related to whether they can find an ideal job. Certainly, the awareness of endowment insurance also directly influences graduates' graduation will. The process that the awareness of endowment insurance becomes strong from weak is also a process that the employment intention is continuously enhanced in various factors, that is, the stronger the awareness of endowment insurance is, the stronger the graduates' requirement for employment intention will be.

Influence of endowment insurance on graduates' employment selection

(1) The endowment insurance causes certain influence on acquisition channel of employment information.

While the graduates carry out employment selection, they shall firstly obtain employment information from outside world, and then accurately carry out employment selection. There are many means for graduates to obtain information; for example, they can obtain employment information from school, teachers, instructors, friends and relatives, and network, etc. Through research and investigation, the awareness of endowment insurance causes small influence on the channels for graduates to obtain employment information, but obtaining employment information through family members, friends, and networks is directly related to the awareness of endowment insurance; other channels cause small influence.

(2) Influence of endowment insurance on graduates' job satisfaction

As the "knowledge-based" labor force, the first job for graduates after graduation will directly influence their future development, thus the job satisfaction is very important for graduates; however, the job satisfaction is influenced by many factors, such as salary, treatment, development space, and various welfare, and the endowment insurance is just one kind of welfare, thus the endowment insurance certainly causes certain influence on job satisfaction. The stronger the awareness of endowment insurance is, the more satisfied the graduates are with the job; in other words, if the welfare of endowment insurance is provided for the graduates' first job, their job satisfaction will be enhanced.

\section{Overall influence of endowment insurance on "knowledge-based" graduates' employment}

With the rapid development of China's market economy, people's living standard obviously increases; however, the employment difficulty follows. Despite of more and more college students, the employment becomes more and more difficult; facing the fierce talent competition in market, the college students have larger and larger employment pressure. As a kind of welfare of enterprises and public institutions, the endowment insurance shall be paid while the graduates are employed, thus it has direct relationship with graduates' employment. Through above analysis on influence of endowment insurance on graduates' employment, it can be seen that the graduates' employment is directly related with their awareness of endowment insurance, and the endowment insurance has direct influence on employment pressure, employment initiative, employment intention, and job satisfaction, etc.; in a word, the stronger the awareness of endowment insurance is, the stronger various employment factors cause influence, which shows that the awareness of endowment insurance attracts people's more and more attention, especially for "knowledge-based" labor force. 


\section{Influence of endowment insurance on in-service personnel's employment}

Except for college graduates, the labor force also includes in-service personnel. The endowment insurance not only causes influence on college students' employment, but also causes direct influence on in-service personnel's re-employment. The social talent demand is increasingly inclined to work experience, thus many in-service personnel select re-employment, that is, the so-called “job-hopping”, which causes great impact on college students’ employment.

1). The endowment insurance causes direct influence on in-service personnel's career. According to relevant research, it can be known that the endowment insurance causes small influence on in-service personnel's career exploration and decision, but causes obvious influence on the adjustment and action in their career.

2). The endowment insurance causes influence on in-service personnel's occupational expectation. As a kind of work welfare, the job with endowment insurance will be close to occupational expectation; in case of no endowment insurance, the job will deviate from occupational expectation. According to the investigation, it can be known that the in-service personnel with endowment insurance have high occupational expectation, and the personnel without endowment insurance will be not satisfied with current occupation and select re-employment, which increases the employment pressure and causes great impact on graduates’ employment.

3). The endowment insurance causes direct influence on in-service personnel's value orientation. The in-service personnel have different opinions for job; for example, someone wants high income, someone pays attention to future development, and someone wants to obtain certain welfare; it is obvious that the endowment insurance, as a kind of social welfare, certainly causes certain influence on their value orientation. People with endowment insurance will pay more attention to work environment, unit property, and income, while people without endowment insurance pay no attention to work environment and other things and only pay attention to place of work. It is obvious that the personnel with endowment insurance have requirements for their work and have stronger intention to realize their value, but the personnel without endowment insurance have no time to consider those things.

4). The endowment insurance influences in-service personnel's job stability. The in-service personnel's re-employment is a very common phenomenon, which also has certain relationship with endowment insurance. As an important social welfare, the endowment insurance more or less influences in-service personnel's job satisfaction, but causes little influence on job stability.

5). The endowment insurance causes direct influence on in-service personnel's career development. Whether there is endowment insurance is greatly related to the property of enterprise; most of foreign-funded, joint-venture, privately operated, and state-owned enterprises provide endowment insurance, but the individual units rarely provide endowment insurance, thus the endowment insurance also symbolizes the strength of one unit and influences the development chance of work. Meanwhile, the work posts directly determine whether there is endowment insurance. For example, generally speaking, the staffs of professional technical post and administrative post are provided with endowment insurance, but there is low possibility for providing staffs of common post with endowment insurance; it is obvious that the endowment insurance is an important fact to divide job nature. Besides, the endowment insurance also influences in-service personnel's job satisfaction. People with endowment insurance have certain guarantee, and people without endowment insurance will be dissatisfied, thus the endowment insurance influences job satisfaction.

\section{Conclusions}

In conclusion, the endowment insurance causes great influence on "knowledge-based" labor employment. This paper starts from two kinds of "knowledge-based" labor to research the influence of endowment insurance, and it can be obtained that the endowment insurance influences college graduates' employment pressure, employment intention, and employment initiative, and influences the in-service personnel's career planning and career development. Therefore, it is required to control 
their relationship and practically solve "employment” and "endowment insurance” problems which attract great social attention.

\section{References}

[1] Gao Zhen: Research of Influence of Endowment Insurance on "Knowledge-based" Labor Employment, Guangxi Normal University, 2014.

[2] Bao Weijie: Influence of China's Urban Endowment Insurance System on Labor Supply, Xiangtan University, 2012.

[3] Tan Yan: Research on Adaptability between Rural Social Endowment Insurance and Economic Development in Shanxi Province, Shanxi University of Finance and Economics, 2012.

[4] Li Xuezeng, Jiang Yuanyuan: Research on Dynamic Economic Effect of Endowment Insurance System "Combined with Social Pooling and Personal Account" - from perspective of analysis on government debt, Research on Financial and Economic Issues, 2014 (4): 68-74.

[5] Li Jingping: Analysis on Coordination between Regional Commercial Endowment Insurance and Social Endowment Insurance, Journal of South-Central University for Nationalities (Humanities and Social Sciences), 2014 (3): 128-131. 